\title{
Entre interdições e possibilidades: uma revisão bibliográfica das práticas online em psicologia nos últimos 21 anos no Brasil
}

\author{
Between interdictions and possibilities: a bibliographic review on online practices in psychology \\ over the last 21 years in Brazil \\ Entre interdicciones y posibilidades: una revisión bibliográfica sobre las prácticas en línea en \\ psicología durante los últimos 21 años en Brasil
}

\section{Resumo}

Com a emergência da pandemia de covid-19 e a necessidade de isolamento social, o Conselho Federal de Psicologia (CFP) recomendou à categoria a suspensão de todas as atividades presenciais em território nacional, exceto aquelas consideradas emergenciais, o que proporcionou mudanças e adequações para a atuação. Com isso, a já crescente discussão acerca do tema se tornou ainda mais urgente. O objetivo desta pesquisa é realizar uma revisão integrativa da literatura no que concerne às práticas psicológicas realizadas de modo online, do ano de 2000 a 2021, no Brasil. Pretendeu-se relacionar as produções encontradas com as discussões propostas pelas normas técnicas lançadas pelo CFP ao longo do tempo. A metodologia utilizada foi a revisão integrativa, dado o seu potencial de sistematizar estudos e permitir a construção de novos conhecimentos, selecionando os trabalhos a partir de plataformas de busca online. Como resultados, percebeu-se que a maioria dos trabalhos retornados apresentam um caráter investigativo, com o intuito de analisar a efetividade dessas práticas, e assim contribuir com as discussões sobre a sua regulamentação. Além disso, pesquisas sobre os aspectos éticos dessa atuação, assim como pesquisas de opinião sobre o tema, foram encontradas. A partir da crescente adesão às tecnologias da informação e comunicação (TICs) e das resoluções publicadas pelo CFP, mais pesquisas específicas surgiram dentro da temática. Avalia-se a necessidade de novas produções que levem em conta diferentes aspectos das práticas online, sobretudo com a urgência desse debate em tempos recentes.

Palavras-chave: Atendimento psicológico online; Práticas psicológicas online; Psicologia online; Saúde mental; Revisão de literatura.

\begin{abstract}
With the emergence of the covid-19 pandemic and the need for social isolation, the Federal Council of Psychology (CFP) recommended to the category the suspension of all face-to-face activities in the national territory, except those considered emergency, which provided changes and adjustments to the acting. With that, the already growing discussion about the subject is even more urgent. The objective of this research is to carry out an integrative literature review regarding psychological practices carried out online, from 2000 to 2021, in Brazil. It was intended to relate the productions found with the discussions proposed by the technical standards launched by the CFP over time. The methodology used was the integrative review, given its potential to systematize studies and allow the construction of new knowledge, selecting works from online search platforms. As a result, it was noticed that most of the works returned have an investigative character, in order to analyze the effectiveness of these practices, and thus contribute to discussions about their regulation. In addition, research on the ethical aspects of this action, as well as opinion polls
\end{abstract}


on the subject, were found. From the growing adherence to information and communication technologies (ICTs) and the resolutions published by the CFP, more specific researches emerged within the theme. The need for new productions on the different aspects of online psychology is evaluated, especially with the urgency of this debate in recent times.

Keywords: Online psychological care; Online psychological practices; Online psychology; Mental health; Literature review.

\section{Resumen}

Con la emergencia de la pandemia del covid-19 y la necesidad de aislamiento social, el Consejo Federal de Psicología (CFP) recomendó a la categoría la suspensión de todas las actividades presenciales en el territorio nacional, excepto las consideradas de emergencia, que preveían cambios y ajustes a la actuación. Con eso, la ya creciente discusión sobre el tema es aún más urgente. El objetivo de esta investigación es realizar una revisión integradora de la literatura sobre las prácticas psicológicas realizadas en línea, de 2000 a 2021, en Brasil. Se pretendía relacionar las producciones encontradas con las discusiones propuestas por las normas técnicas lanzadas por la PPC a lo largo del tiempo. La metodología utilizada fue la revisión integradora, dado su potencial para sistematizar estudios y permitir la construcción de nuevos conocimientos, seleccionando trabajos desde plataformas de búsqueda en línea. Como resultado, se notó que la mayoría de los trabajos devueltos tienen un carácter investigativo, con el fin de analizar la efectividad de estas prácticas, y así contribuir a las discusiones sobre su regulación. Además, se encontraron investigaciones sobre los aspectos éticos, así como sondeos de opinión sobre el tema. A partir de la creciente adhesión a las tecnologías de la información y la comunicación (TIC) y las resoluciones publicadas por la PPC, han surgido investigaciones más específicas dentro del tema. Se evalúa la necesidad de nuevas producciones sobre los diferentes aspectos de la práctica psicológica en el entorno online, especialmente con la urgencia de este debate.

Palabras clave: Atención psicológica en línea; Prácticas psicológicas en línea; Psicología en línea; Salud mental; Revisión de literatura.

\section{Introdução}

Em decorrência da pandemia de covid-19 no Brasil, e a partir de evidências científicas que indicavam que o isolamento poderia conter ou reduzir a contaminação pelo vírus (Aquino et al, 2020), as autoridades governamentais e os órgãos de saúde passaram a incentivar políticas de distanciamento social, incluindo a suspensão das atividades em escolas e universidades, proibição de aglomerações em eventos e festas, restrição de viagens e uso de transportes públicos, entre outras. Estas medidas foram adotadas em diferentes intensidades pelos países e mesmo em territórios brasileiros. No entanto, a sua adoção não foi universal, sendo muitas vezes incentivada pelos estados e municípios no contexto brasileiro de forma independente da federação (Moraes, 2021; Aquino et al, 2020).

Neste contexto, uma das práticas que precisou se reconstruir foi o atendimento psicológico. Houve um aumento de demandas de saúde mental e da procura pelo atendimento online nos meses de maior isolamento social imposto pela pandemia (Viana, 2020), o que ocasionou certa apreensão e preocupação por parte da categoria de profissionais de psicologia, resultando em tensões e discussões sobre o tema, seus entraves e possibilidades.

Apesar de ser regulamentada desde 2000, com a Resolução No 003/2000, a atividade online da/o profissional de psicologia não era tão frequente e continha diversas limitações, o que foi se modificando com o avanço das tecnologias de informação e comunicação (TICs). Assim, viu-se a necessidade de adequações legislativas por parte do CFP, bem como de criação de plataformas e serviços para dar conta do crescimento da demanda percebida.

A regulamentação referente à realização de atendimento psicoterapêutico e outras práticas psicológicas de forma online se iniciou com as resoluções $n^{\circ}$ 003/2000, nº 012/2005 e n 011/2012, do Conselho Federal de Psicologia (2000; 2005; 2012). O panorama colocado tratava de uma psicoterapia de caráter apenas experimental, pois, segundo o CFP, a prática ainda não era reconhecida dentro do campo da psicologia e acreditava-se que deveria ser melhor estudada. Inicialmente, a atividade deveria ser feita a partir do respeito a diversas condições, como a passagem e aprovação da prática por comitês de ética, sendo restrita ao âmbito da pesquisa, sendo obrigatório entre outras fazer parte de projeto de pesquisa, ter aprovação de Comitê de Ética, ser gratuita (CFP, 2005). Entretanto, a mesma legislação reconhece como prática legal e passível de remuneração outros serviços psicológicos mediados por computador desde que possuam caráter pontual e informativo, tais como orientação 
psicológica e afetivo-sexual, orientação profissional, orientação de aprendizagem e Psicologia escolar, orientação ergonômica, consultorias a empresas, reabilitação cognitiva, ideomotora e comunicativa, processos prévios de seleção de pessoal, utilização de testes psicológicos informatizados com avaliação favorável de acordo com Resolução $\mathrm{N}^{\circ}$ 002/03, utilização de softwares informativos e educativos com resposta automatizada. O caráter experimental das resoluções criou um campo fértil para a execução de diversos estudos que endossaram a necessidade de regulamentação do serviço para além das práticas de pesquisa, pois demonstraram a possibilidade de criação de vínculo terapêutico e a efetividade do tratamento também quando mediado por eletrônicos (Bittencourt et al, 2020).

Apesar de a Resolução $N^{\circ}$ 011/2012, que revogou as anteriores, ter trazido maior flexibilização em relação aos serviços psicológicos, a realização integral de atendimentos psicoterapêuticos ainda era permitida apenas em caráter experimental. Foi apenas no ano de 2018 que uma nova resolução acerca do tema, a Resolução No 011/2018, foi publicada. Esta resolução trouxe alterações que ampliaram as possibilidades da prática psicológica online, tais como a retirada do limite do número de sessões, a possibilidade de atendimento de crianças e adolescentes, permitido mediante consentimento dos responsáveis, entre outros (CFP, 2018). No entanto, o atendimento de pessoas vítimas de violência foi vetado, sendo permitido apenas de forma presencial.

O CFP publicou, em 26 de março de 2020 a Resolução $N^{\circ}$ 04/2020, cujo objetivo foi regulamentar os serviços psicológicos realizados por meio das tecnologias de informação e comunicação durante a pandemia do covid-19, suspendendo o Art. $3^{\circ}$ ao Art. $8^{\circ}$ da Resolução $N^{\circ} 011$ de 2018 por esse período, e condicionando a prestação dos serviços psicológicos online ao cadastro na plataforma e-Psi, atrelada ao CFP, havendo a necessidade de um parecer emitido pelo CFP e a necessidade de um cadastro atualizado para a realização destes serviços (CFP, 2020a).

Com a necessidade de respeitar as medidas de isolamento social e compreendendo seus impactos à atuação da profissão, o sistema Conselhos, em suas diferentes instâncias, realizou diversos debates e a publicação de alguns materiais ao longo dos anos de 2020 e 2021. Dentre estes, algumas recomendações e cartilhas orientando as práticas relacionadas à psicologia no contexto da pandemia, como os estágios e avaliações psicológicas. Em novembro de 2020, o CFP publicou algumas notas técnicas relacionadas ao âmbito da avaliação psicológica, contendo orientações frente à pandemia. Uma destas apresenta considerações sobre o uso de testes psicológicos informatizados e/ou de aplicação online, colocando como necessário de testes que ofereçam a possibilidade deste tipo de publicação que possuam estudos específicos que garantem a presença de propriedades psicométricas para a aplicação a partir desses meios (CFP, 2020d). Retoma-se um trecho da nota técnica 07/2019, que coloca a diferença entre uma aplicação informatizada, por meio de um computador, de um teste e a aplicação online, de forma remota, mas ainda utilizando instrumentos como papel e caneta. Com isso, coloca-se como papel do profissional a análise do teste para definição da forma de aplicação que é recomendada ao mesmo, levando em conta tal diferença (CFP, 2020d).

É importante também apontar que a nota técnica 07/2019 atenta para a necessidade de verificar quais os testes validados e aprovados pelo Sistema de Avaliação de Testes Psicológicos (SATEPSI), bem como para a utilização da plataforma do SATEPSI para a verificação dos status de testes selecionados para a sua aplicação a partir dos meios citados anteriormente. Outra nota publicada no mesmo mês e ano, a Nota Orientativa sobre ensino da Avaliação Psicológica em modalidade remota no contexto da pandemia de covid-19, trata da presente questão. As orientações colocadas incluem evitar a realização de atividades que "tragam informações sobre a aplicação, correção e interpretação de testes psicológicos, bem como tabelas normativas ou partes de manual", visto que o ensino sobre a aplicação de testes é restrito a modalidade presencial, conforme o Código de Ética, com o intuito de preservar o sigilo dos testes (CFP, 2020d). O documento também faz uma menção à necessidade de respeitar normas colocadas sobre estágios e práticas, devendo ocorrer de forma exclusivamente presencial, de forma a respeitar os princípios da formação em psicologia (CFP, 2020d). Essa menção aparece como pouco 
desenvolvida e explicitada, não fazendo referência a nenhuma outra produção que discuta a realização dos estágios no período de pandemia.

Em meio a essas referências há uma publicação do CFP intitulada "Práticas e Estágios Remotos em Psicologia no Contexto da Pandemia de covid-19: Recomendações”, que parte de determinações contidas em portarias do Ministério da Educação. Através desta publicação, o CFP aponta ser capaz de recomendar apenas determinadas ações, visto que a regulamentação dos cursos de graduação do Brasil é estritamente de responsabilidade do MEC e do Conselho Nacional de Educação (CNE). A portaria de nº 544 do MEC, também de 2020, prevê a substituição de práticas profissionais como estágios para atividades que utilizem as TICs, desde que os cursos estejam de acordo com as Diretrizes Nacionais Curriculares do CNE. Também, coloca-se como necessária à realização dos estágios remotos a produção de planos de trabalho específicos, aprovados pelos respectivos colegiados do curso (MEC, 2020). No documento citado acima, dentre as principais recomendações feitas aos psicólogos supervisores, está a de que a prática remota deve ser minimizada tanto quanto possível, de modo a privilegiar experiências profissionais na formação. E tratando especificamente dos serviços-escola, a sugestão é para que os seus espaços sejam utilizados para as atividades de clínica remota e de avaliação psicológica, garantidas as condições de biossegurança dos estagiários e supervisores (CFP, 2020c).

Mediante às publicações e resoluções do CFP e das mudanças por elas geradas, observa-se a manutenção de um terreno fértil à investigação e discussão da prática profissional nesse contexto, levando em consideração, sobretudo, os novos desafios colocados pela conjuntura atual. Nessa perspectiva, esta pesquisa tem como objetivo acompanhar o desenvolvimento de produções acadêmicas acerca do tema nos últimos anos (2000-2021), em consonância com as resoluções do CFP e levando em conta os contextos sociais durante os quais os estudos foram publicados.

A partir disso, a presente pesquisa foi guiada pelo questionamento a respeito de quais as principais questões discutidas no tocante ao atendimento psicológico online, discutindo as possíveis contribuições ao campo da psicologia de maneira geral, bem como as contribuições que podem ser úteis nessa conjuntura de ampla utilização no meio online para a realização das práticas e serviços psicológicos em meio ao contexto pandêmico.

\section{Metodologia}

A fim de obter uma perspectiva ampla sobre o tema a ser debatido, optou-se pela abordagem de revisão integrativa. Souza, Silva e Carvalho (2010) discutem que este tipo de revisão demonstra completude, possibilitando a análise de grande variedade de trabalhos, como experimentais e não experimentais, unindo dados teóricos e empíricos. Sobre a revisão integrativa, as autoras também apontam sua utilidade na abordagem de uma ampla gama de propósitos contidos em diferentes trabalhos, tais como: definição de conceitos, revisão de teorias e evidências e a análise de problemas metodológicos que dizem respeito a um tópico particular. A revisão integrativa, portanto, apresenta-se como uma metodologia que fornece uma síntese do conhecimento, bem como uma possibilidade de incorporação de resultados de estudos significativos na prática (Souza, Silva e Carvalho, 2010).

Uma revisão integrativa busca também traçar uma síntese e análise a respeito do conhecimento que já fora construído em trabalhos anteriores sobre o tema (Costa Pita et al, 2021; Rezende, Alves \& Rabelo, 2021). Botelho et al (2011) apontam a possibilidade de síntese desses estudos e a geração de novos conhecimentos com base em seus achados através dessa metodologia. A revisão integrativa consiste na construção de uma análise ampla da literatura, contribuindo para discussões sobre métodos e resultados de pesquisas, podendo-se identificar lacunas de conhecimento, levantar o conhecimento já produzido e indicar prioridades para futuros estudos (Mendes, Silveira \& Galvão, 2008; Paiva et al, 2016).

As etapas de elaboração da revisão integrativa encontram-se bem descritas na literatura; no entanto, diversos autores sugerem outras divisões e modificações (Mendes, Silveira e Galvão, 2008; Botelho, Cunha \& Macedo, 2011). Ribeiro et al 
(2012) apontam seis passos para a revisão: a primeira sendo a seleção da questão para a revisão; a seleção das pesquisas que farão parte da amostra do estudo; a representação das características das pesquisas revisadas; análise dos achados conforme critérios de inclusão e exclusão determinados no projeto; a interpretação dos resultados; e a apresentação e divulgação dos resultados.

A coleta de dados ocorreu no período de 2 a 10 julho de 2021 em seis plataformas, a saber: a Biblioteca Virtual em Saúde (BVS), o portal de Periódicos Eletrônicos de Psicologia (PePSIC), a Scientific Electronic Library Online (SciELO), a Biblioteca Digital Brasileira de Teses e Dissertações (BDTD), o Portal de Periódicos CAPES (CAPES) e a Red de Revistas Científicas de América Latina y el Caribe, España y Portugal (Redalyc).

A busca dos artigos foi realizada respeitando as especificidades de cada base de dados, utilizando-se os seguintes descritores: Atendimento Psicológico Online; Atendimento Psicológico On-line; Psicologia e Atendimento Online; Psicologia e Atendimento On-line; Psicoterapia Online; Psicoterapia On-line; Psicologia Online; Psicologia On-line; Terapia Online; Terapia On-line; Prática Psicológica Online; Prática Psicológica On-line; Psicoterapia Virtual; Psicoterapia Remota; e Atendimento Psicológico Eletrônico. Considerando as diferentes grafias possíveis para o termo online (online e on-line) optouse pelo uso de ambas, entendendo-se que a escolha de uma em detrimento da outra poderia ocasionar a perda de resultados. Os trabalhos foram selecionados a partir da leitura dos resumos disponíveis nas bases de dados eletrônicas apontadas anteriormente.

Já para a inclusão/exclusão de trabalhos foram estabelecidos os seguintes critérios: trabalhos que tratam do tema em contexto brasileiro, publicados entre os anos de 2000 a 2021 no idioma português e pelo menos um/a dos/as autores/as ser profissional de psicologia. Excluiu-se relatos informais e não científicos, outras revisões de literatura, publicações repetidas e trabalhos que não foram produzidos por pelo menos um(a) profissional de psicologia e trabalhos que não estavam disponíveis na íntegra.

Os resultados foram organizados em um quadro para a análise dos artigos selecionados, contendo informações relevantes à pesquisa, a saber: Autoria, título do trabalho, revista ou instituição de publicação, região e estado de filiação do/a primeira autor/a. Estes resultados foram, após leitura na íntegra, apresentados e discutidos de forma descritiva, conforme o objetivo desta revisão.

\section{Resultados}

A partir da pesquisa nas seis plataformas já citadas, foram retornados 2.517 trabalhos. Assim, necessitou-se de um processo de filtragem, ilustrado no fluxograma da Figura 1, adaptado do Reporting Items Systematic and Meta-Analyses (PRISMA). Os resultados obtidos pela pesquisa somaram 2517 — o fato de alguns resultados se mostrarem indexados em mais de uma das plataformas pode oferecer indícios do grande número de retornos. Esses 2517 trabalhos seguiram por uma seleção com base nos critérios desta revisão, excluindo-se estudos que tratavam de revisões, não se referiam ao contexto brasileiro, trabalhos repetidos e que não estivessem disponíveis para o acesso na íntegra, restando vinte e sete trabalhos. Estes foram lidos integralmente, em observância com a temática de interesse desta revisão e, a partir desse processo, oito estudos foram excluídos da seleção. Ao final, foram incluídos dezenove trabalhos, sendo oito deles da Biblioteca Digital Brasileira de Teses e Dissertações (BDTD), seis do portal de Periódicos Eletrônicos de Psicologia (PePSIC), dois da Red de Revistas Científicas de América Latina y el Caribe, España y Portugal (Redalyc), um da Biblioteca Virtual em Saúde (BVS), um do Portal de Periódicos CAPES (CAPES) e um resultado da Scientific Electronic Library Online (SciELO). 
Figura 1. Fluxograma de seleção de artigos nas bases de dados.

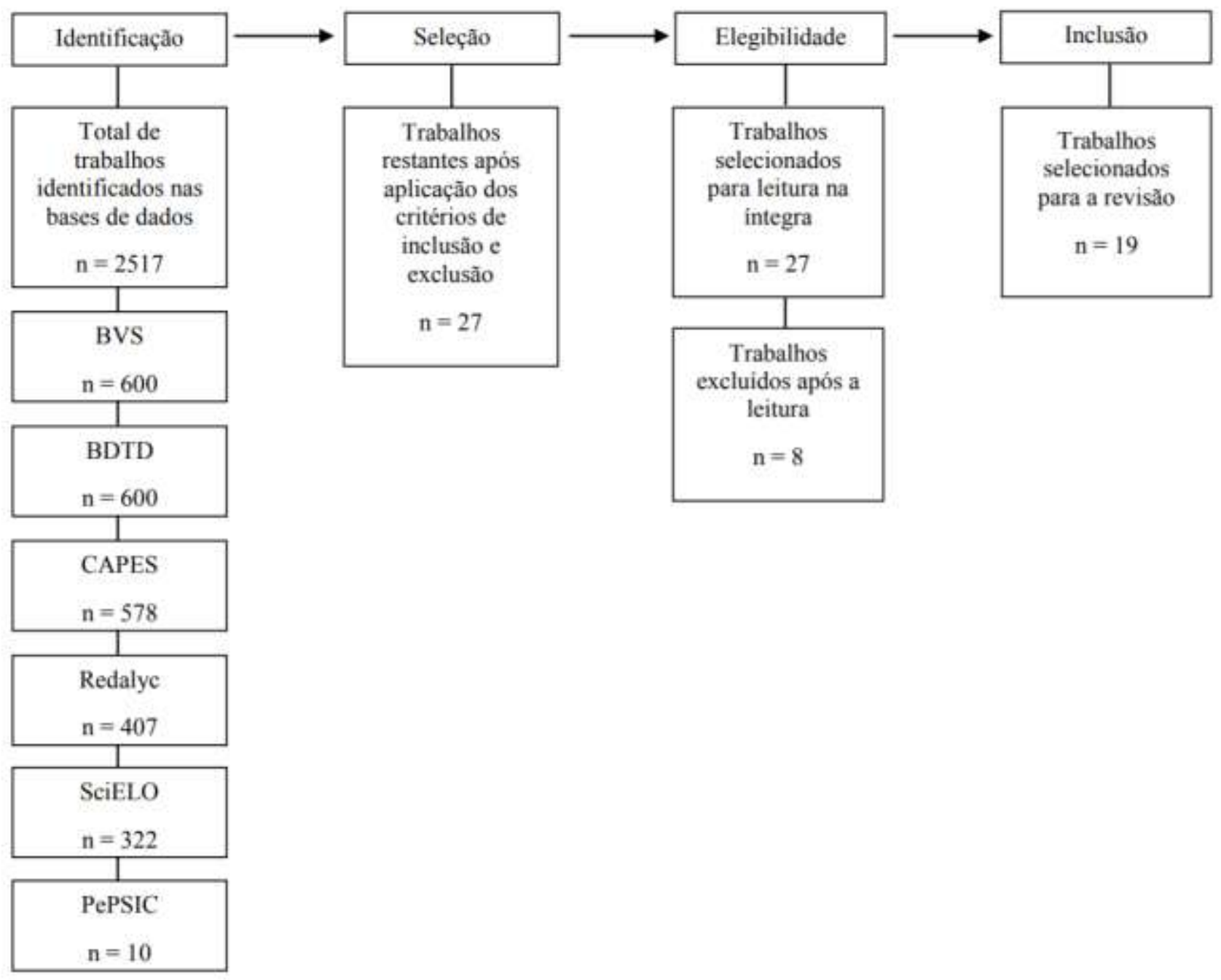

nte: Autores (2021).

Entre os anos de 2001 e 2010, foram encontradas apenas três obras, enquanto que a maioria dos estudos foram publicados entre os anos de 2011 e 2020, sendo estes 16. Dos dezenove trabalhos, cinco são de 2015 (26\%), três são de 2016 (16\%), dois do ano de 2014 (11\%), dois de 2019 (11\%) e também dois de 2020 (11\%). Os anos de 2002, 2003, 2008, 2011 e 2013 com um trabalho cada ano, correspondem a 25\% das produções, 5\% cada ano. Já para os anos de 2004, 2005, 2006, 2007, 2012, 2017, 2018 e 2021 não foi encontrada nenhuma publicação que correspondesse aos critérios de inclusão dessa pesquisa. A maior parte dos estudos, dez dos dezenove, foram publicados por autoras/es filiadas/os ou advindas/os de instituições da região Sudeste (53\%), seguida da região Sul (26\%) com cinco publicações, de três publicações da região Centro-oeste (16\%) e da região Nordeste com uma produção, equivalente a 5\% das produções selecionadas. Nenhum dos trabalhos foi publicado por autoras/es de instituições da região Norte.

Os trabalhos que buscaram investigar a eficácia do atendimento psicológico realizado no formato online, principalmente no que diz respeito às possibilidades de construção de uma aliança terapêutica, como é o caso dos estudos de Pieta (2014), que busca explorar limites e potencialidades do atendimento psicológico clínico online, com foco na análise da eficácia do tratamento e construção da aliança terapêutica, e Rodrigues (2014), que tem por objetivo analisar a aliança terapêutica estabelecida exclusivamente via internet. O estudo de Pieta (2014) demonstrou que a construção de uma aliança 
terapêutica no meio online carrega os mesmos desafios e potencialidades do modelo presencial. No estudo de Rodrigues (2014), apesar dos pacientes relatarem acreditar que a psicoterapia online apresenta limitações no que diz respeito ao atendimento de pessoas em situação de crise, estes também apontaram para aspectos positivos desse formato, como a comodidade de realizar um tratamento à distância. Ambos os estudos concluíram que a prática realizada na modalidade online apresenta boa eficácia.

Também foram encontrados estudos que visavam investigar a percepção da comunidade sobre a realização de práticas psicológicas online, como o de Marot e Ferreira (2008), que investigou atitudes em relação à aprovação da psicoterapia online, e concluiu uma ambiguidade no que diz respeito ao conjunto de crenças relacionados à essa aprovação. Já o estudo de Silva e Ribeiro-Andrade (2015) procurou conhecer a opinião de moradores de uma cidade do Rio de Janeiro acerca da psicoterapia mediada por computador, e demonstrou certo receio por parte desta população à prática. $\mathrm{O}$ de Barletta e Machado (2015), por sua vez, focou em explorar a percepção dos alunos acerca das supervisões em atendimento clínico ocorridas de forma online, e mostrou a efetividade da supervisão em ambas as modalidades, apesar da falta de conhecimento acerca do EaD.

Já Gerson Siegmund e Carolina Lisboa (2015) e Magalhães, Bazoni e Pereira (2019) investigaram as percepções de psicólogos(as) acerca da orientação psicológica on-line, e relataram que a orientação psicológica pela internet constitui uma forma de trabalho secundária, complementar à atividade de trabalho principal dos profissionais (Siegmund e Lisboa, 2015; Pereira et al, 2015) e a necessidade de mais estudos sobre o tema (Bazoni; Magalhães; Pereira, 2019). A prática online foi investigada ainda por Santos (2003), que buscou as opiniões de profissionais da psicologia, e demonstrou que são divididas em relação a vários aspectos da prática, incluindo o interesse e a motivação para se trabalhar dessa forma.

Diferentes abordagens terapêuticas estiveram presentes nos trabalhos retornados, como no estudo de Singulane (2016), que teve por objetivo avaliar a aliança terapêutica e a satisfação com o tratamento em uma psicoterapia por videoconferência para dependentes de álcool à luz da Terapia Cognitiva Comportamental, e indicou a formação de uma aliança de qualidade e satisfação dos clientes com o tratamento, e o de Donnamaria e Terzis (2013) que buscou analisar experiências de atendimento em grupo pela internet, sob a perspectiva da psicanálise, demonstrando que as experiências grupais online conseguem manter vários benefícios do modelo presencial, mesmo com limitações. Além disso, os estudos de Vidal e Cardoso (2020) e Vidal e Castro (2020) procuraram analisar as possibilidades do psicodrama no meio online, mostrando-se favorável à prática. Donnamaria e Terzis (2011) também exploraram e discutiram uma pesquisa não finalizada com a prática da terapia em grupo online, trazendo aspectos éticos em suas reflexões, e concluíram que a prática de terapia online tem possibilidade nesse campo (virtual), e, portanto, negá-la seria afrontar o novo. A publicação de Donnamaria e Terzis do ano de 2013, faz parte da mesma pesquisa das autoras realizada em 2011, mas traz novas informações, e por isso também foi incluída no presente trabalho.

O Quadro 1 apresenta a relação dos trabalhos selecionados para a análise nesta pesquisa, com: autoria e ano, título do trabalho, revista ou instituição de publicação, região e estado em que o trabalho foi publicado e plataforma de indexação. 
Quadro 1. Caracterização das produções incluídas nesta revisão integrativa.

\begin{tabular}{|c|c|c|c|c|}
\hline Autor/Ano & Título do trabalho & $\begin{array}{l}\text { Revista/Instituição de } \\
\text { Publicação }\end{array}$ & $\begin{array}{c}\text { Região/Estado de } \\
\text { Filiação do/a primeiro } \\
\text { autor/a }\end{array}$ & Plataforma de indexação \\
\hline Pinto, E. R./ 2002 & $\begin{array}{l}\text { As modalidades do atendimento } \\
\text { psicológico on-line }\end{array}$ & Temas em Psicologia & Sudeste/Rio de Janeiro & $\begin{array}{ll}\text { Portal de } & \text { Periódicos } \\
\text { Eletrônicos de } & \text { Psicologia } \\
\text { (PePSIC) } & \end{array}$ \\
\hline $\begin{array}{l}\text { Santos, A. P. C. } \\
\text { D./2003 }\end{array}$ & $\begin{array}{l}\text { Psicoterapia na Rede: Um estudo } \\
\text { sobre a clínica mediada pelo } \\
\text { computador }\end{array}$ & $\begin{array}{l}\text { Pontifícia Universidade Católica } \\
\text { do Rio de Janeiro (Dissertação) }\end{array}$ & Sudeste/Rio de Janeiro & 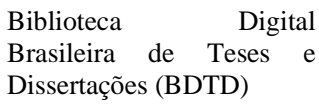 \\
\hline $\begin{array}{l}\text { Marot, R. S. V. \& } \\
\text { Ferreira, M. C. } / 2008\end{array}$ & $\begin{array}{l}\text { Atitudes sobre a aprovação da } \\
\text { psicoterapia online na perspectivada } \\
\text { Teoria da Ação Racional }\end{array}$ & $\begin{array}{l}\text { Interamerican Journal of } \\
\text { Psychology }\end{array}$ & Sudeste/Rio de Janeiro & PePSIC \\
\hline $\begin{array}{l}\text { Donnamaria, C. P. \& } \\
\text { Terzis, A./2011 }\end{array}$ & $\begin{array}{l}\text { Experimentando o dispositivo } \\
\text { terapêutico de grupo via internet: } \\
\text { primeiras considerações de manejo e } \\
\text { desafios éticos }\end{array}$ &  & Sudeste/São Paulo & PePSIC \\
\hline $\begin{array}{l}\text { Donnamaria, C. P. } \\
2013\end{array}$ & $\begin{array}{l}\text { Experiências de atendimento } \\
\text { psicológico grupal via internet: uma } \\
\text { perspectiva psicanalítica }\end{array}$ & $\begin{array}{l}\text { Pontifícia Universidade Católica } \\
\text { de Campinas (Tese) }\end{array}$ & Sudeste/São Paulo & BDTD \\
\hline Pieta, M. A. M./2014 & $\begin{array}{l}\text { Psicoterapia pela internet: a relação } \\
\text { terapêutica }\end{array}$ & $\begin{array}{l}\text { Universidade Federal do Rio } \\
\text { Grande do Sul (Tese) }\end{array}$ & Sul/Rio Grande do Sul & BDTD \\
\hline Rodrigues, C. G./2014 & $\begin{array}{l}\text { Aliança terapêutica na psicoterapia } \\
\text { breve online }\end{array}$ & $\begin{array}{l}\text { Universidade } \\
\text { (Dissertação) }\end{array} \quad$ de $\quad$ Brasília & $\begin{array}{l}\text { Centro-Oeste/Distrito } \\
\text { Federal }\end{array}$ & BDTD \\
\hline $\begin{array}{l}\text { Azevedo, B. B.; Silva, } \\
\text { É. Q.; Ribeiro- } \\
\text { Andrade, É. H } / 2015\end{array}$ & $\begin{array}{l}\text { Estudos sobre a psicoterapia } \\
\text { mediada por computador }\end{array}$ & $\begin{array}{l}\text { Perspectivas Online: Humanas \& } \\
\text { Sociais Aplicadas (POHSA) }\end{array}$ & Sudeste/Rio de Janeiro & $\begin{array}{l}\text { Portal de Periódicos } \\
\text { CAPES (CAPES) }\end{array}$ \\
\hline Gumier, A. B./2015 & $\begin{array}{l}\text { Terapia por internet para } \\
\text { dependentes } \\
\text { desenvolvimento de um protocolo de } \\
\text { um ensaio clínico randomizado }\end{array}$ & $\begin{array}{l}\text { Universidade Federal de Juiz de } \\
\text { Fora (Dissertação) }\end{array}$ & Sudeste/Minas Gerais & BDTD \\
\hline $\begin{array}{l}\text { Machado, G. I. M. D. } \\
\text { S. \& Barletta, J. } \\
\text { B./2015 }\end{array}$ & $\begin{array}{l}\text { Supervisão clínica presencial e } \\
\text { online: percepção de estudantes de } \\
\text { especialização }\end{array}$ & $\begin{array}{l}\text { Revista Brasileira de Terapias } \\
\text { Cognitivas }\end{array}$ & Nordeste/Sergipe & PePSIC \\
\hline $\begin{array}{l}\text { Siegmund, G., Janzen, } \\
\text { M. R.; Gomes, W. B. } \\
\text { \& Gauer, G./2015 }\end{array}$ & $\begin{array}{l}\text { Aspectos éticos das intervenções } \\
\text { psicológicas online no Brasil: } \\
\text { Situação atual e desafios }\end{array}$ & Psicologia em Estudo (Online) & Sul/Rio Grande do Sul & $\begin{array}{l}\text { Red de Revistas Científicas } \\
\text { de América Latina y el } \\
\text { Caribe, España y Portugal } \\
\text { (Redalyc) }\end{array}$ \\
\hline $\begin{array}{l}\text { Siegmund, G. } \quad \& \\
\text { Lisboa, C./2015 }\end{array}$ & $\begin{array}{l}\text { Orientação Psicológica On-line: } \\
\text { Percepção dos Profissionais sobre a } \\
\text { Relação com os Clientes }\end{array}$ & Psicologia: Ciência e Profissão & Sul/Rio Grande do Sul & $\begin{array}{l}\text { Scientific } \quad \text { Electronic } \\
\text { Library Online (SciELO) }\end{array}$ \\
\hline $\begin{array}{l}\text { Rodrigues, C. G. \& } \\
\text { Tavares, M. A./2016 }\end{array}$ & $\begin{array}{l}\text { Psicoterapia online: demanda } \\
\text { crescente e } \\
\text { regulamentação }\end{array}$ & Psicologia em Estudo (Online) & Sul/São Paulo & Redalyc \\
\hline Ruffo, L./2016 & $\begin{array}{l}\text { Ensaios para compreensão de uma } \\
\text { prática psicológica em construção: } \\
\text { Atendimento Online (via e-mail) }\end{array}$ & $\begin{array}{l}\text { Universidade de São Paulo } \\
\text { (Dissertação) }\end{array}$ & Sudeste / São Paulo & BDTD \\
\hline $\begin{array}{l}\text { Singulane, B. A. } \\
\text { R./2016 }\end{array}$ & $\begin{array}{l}\text { Aliança terapêutica e satisfação com } \\
\text { o tratamento na psicoterapia por } \\
\text { internet para dependentes de álcool }\end{array}$ & $\begin{array}{l}\text { Universidade Federal de Juiz de } \\
\text { Fora (Dissertação) }\end{array}$ & Sudeste/Minas Gerais & BDTD \\
\hline $\begin{array}{l}\text { Galvão, M. G. } \\
\text { A./2019 }\end{array}$ & $\begin{array}{l}\text { Atendimento online em clínica do } \\
\text { trabalho: estudo exploratório }\end{array}$ & $\begin{array}{l}\text { Universidade } \\
\text { (Dissertação) }\end{array}$ & $\begin{array}{l}\text { Centro-oeste/Distrito } \\
\text { Federal }\end{array}$ & BDTD \\
\hline 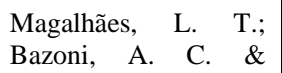 & $\begin{array}{l}\text { Impressões de psicólogos clínicos } \\
\text { acerca da orientação psicológica }\end{array}$ & $\begin{array}{l}\text { Revista Brasileira de Psicoterapia } \\
\text { (Online) }\end{array}$ & Sul/Rio Grande do Sul & $\begin{array}{l}\text { Biblioteca Virtual em } \\
\text { Saúde (BVS) }\end{array}$ \\
\hline
\end{tabular}




\begin{tabular}{|c|c|c|c|c|}
\hline Pereira, F. N./2019 & online & & & \\
\hline $\begin{array}{l}\text { Vidal, G. } \quad \text { P. \& } \\
\text { Cardoso, }\end{array}$ & $\begin{array}{l}\text { Dramatização on-line: psicoterapia } \\
\text { da relação e psicodrama interno no } \\
\text { psicodrama contemporâneo }\end{array}$ & Revista Brasileira de Psicodrama & Sul/Santa Catarina & PePSIC \\
\hline $\begin{array}{l}\text { Vidal, G. P. \& Castro, } \\
\text { A. } 2020\end{array}$ & $\begin{array}{l}\text { O psicodrama clínico on-line: uma } \\
\text { conexão possível }\end{array}$ & Revista Brasileira de Psicodrama & Sudeste/São Paulo & PePSIC \\
\hline
\end{tabular}

Fonte: Autores (2021).

\section{Discussão}

No desenvolver da análise das produções foi possível perceber a escassez de trabalhos nos primeiros anos a que se refere esta pesquisa: até o ano de 2010 foram encontradas apenas três publicações. É necessário destacar que neste período haviam sido publicadas duas resoluções sobre o tema. Já nos anos de 2011 até 2020 foram publicados mais trabalhos, correspondendo a quinze dos que foram selecionados nesta revisão. Os trabalhos iniciais partiam de um contexto em que as diretrizes do CFP só permitiam a psicoterapia online em caráter experimental, apenas em um contexto de pesquisa, como referido anteriormente. A realização da psicoterapia online estava submetida a um rígido protocolo de cadastramento e submissão a comitês de ética, e o conteúdo de determinados trabalhos refletem o caráter tão inicial da inserção da prática de profissionais de psicologia no ambiente virtual, tanto fazendo um apanhado sobre as possibilidades dessas práticas (Pinto, 2002) como buscando opiniões sobre uma das principais ocupações de psicólogos - a psicoterapia - na modalidade online (Santos, 2003; Marot \& Ferreira, 2008).

Donnamaria e Terzis (2011) discutem o contexto da última resolução do CFP à época, promulgada em 2005. Utilizam-na para contextualizar a escassez de estudos e práticas de psicologia online e justificar o estudo da experimentação do dispositivo grupal terapêutico no modelo virtual. Já no ano seguinte, em 2012, foi promulgada a próxima resolução sobre o tema, que traz a novidade de possibilitar a psicoterapia online em outra situação que não a de pesquisa, no caso de clientes que, por algum motivo, não possam comparecer presencialmente por um determinado período de tempo (CFP, 2012). Outras práticas citadas anteriormente, como a orientação psicológica e consultoria, seguem presentes e distintas da psicoterapia experimental.

Os trabalhos publicados até este ano se voltavam à prática terapêutica, aparentemente como uma tentativa de avanço na regulamentação dessa área através da pesquisa científica. Do período de divulgação da resolução de 2012 até a seguinte, em 2018, foi publicada a maior quantidade de trabalhos, sendo dez, somando artigos, teses e dissertações. Os conteúdos desses trabalhos são mais variados, incluindo a pesquisa de Azevedo, Silva \& Ribeiro-Andrade (2015) acerca de opiniões sobre a psicoterapia online, de Donnamaria (2013), que trata de um relato de experiência com grupo sob a perspectiva psicanalítica (Donnamaria, 2013), de Gumier (2015) e de Singulane (2016), ambos sobre trabalhos com dependentes de álcool, investigação sobre o atendimento online via e-mail (Ruffo, 2016), uma análise sobre a questão da aliança terapêutica nesse contexto (Singulane, 2016) e a situação ética atual do Brasil acerca do atendimento psicológico virtual (Siegmund, Janzen, Gomes \& Gauer, 2015). Outros trabalhos também investigam as práticas da supervisão clínica (Machado \& Barleta, 2015) e da orientação psicológica (Siegmund \& Lisboa, 2015) no âmbito online.

É importante notar que as produções tomam autonomia e promovem um enriquecimento importante para o debate do tema das práticas psicológicas online, como nos trabalhos de foco terapêutico, que se apoiam em abordagens específicas, tratando de grupos delimitados, como pessoas em relação abusiva com álcool, e aqueles que tratam de outras práticas, como a supervisão clínica e a orientação psicológica. Em 2018, o uso da internet já havia se expandido ainda mais, incluindo seu uso na educação, trabalho, comunicação e entretenimento; é neste ano que o CFP promulga a Resolução No 11/2018, ampliando as 
ideias sobre meios de comunicação e sistematizando quatro serviços possíveis de serem prestados por meios tecnológicos de comunicação: consulta e/ou atendimento psicológico, processos de seleção de pessoal, utilização de testes psicológicos aprovados pelo Sistema de Avaliação de Instrumentos Psicológicos (SATEPSI) e supervisão técnica. Também são trazidas algumas restrições para o atendimento psicológico online, como a prática com crianças e adolescentes, pessoas em situação de urgência, emergência, desastres e em situação de violação de direitos e violência; no primeiro caso, há a necessidade do consentimento de pelo menos um dos pais para o serviço com menores, e quanto aos outros casos, a prática é vedada.

Os trabalhos seguintes à essa resolução trataram ainda de impressões de psicólogos sobre prática online (Magalhães, Bazoni \& Pereira, 2019), a investigação do contexto específico da clínica do trabalho (Galvão, 2019) e sobre a prática online da abordagem do psicodrama (Vidal \& Cardoso, 2020; Vidal \& Castro, 2020). Estes últimos trabalhos correspondem ao período em que se instalou a pandemia de covid-19 no mundo, quando o CFP precisou de uma resolução que desse conta das demandas mais atuais advindas desse problema de saúde pública.

Dessa forma, em março de 2020 foi publicada a Resolução No 04/2020, que permite que os profissionais da psicologia atuem sem esperar a aprovação de seus cadastros na plataforma regulamentada pelos conselhos regionais, devido à situação de isolamento social imposta pelo vírus, que trouxe grande tráfego e demanda para a plataforma. Ela também suspende os artigos da resolução de 2018 que impediam o serviço a grupos de pessoas em situações específicas (emergências, desastres, violação de direitos). No entanto, não foram encontrados trabalhos que se correspondessem aos critérios de inclusão para esta pesquisa após a data desta resolução e até a data da busca de dados.

Pelo fato da prática psicológica online tratar-se, ao longo de muitos anos, de uma prática nova e desconhecida, muitos foram os embates em relação à perspectiva de sua execução, e por isso a maioria dos trabalhos produzidos sobre o tema até meados do ano 2020 possuem um caráter mais experimental e exploratório, com vistas a investigar a eficácia e a possibilidade de adesão dessa prática pelos profissionais de psicologia, buscando assim contribuir para os debates em torno de sua regulamentação.

Alguns dos principais questionamentos surgidos nos trabalhos dizem respeito às implicações de uma "presença incorpórea" na vivência do setting terapêutico, o que pode ganhar diferentes contornos ao levar-se em conta as distintas maneiras de se fazer um encontro psicoterapêutico de forma online, que vão desde a realização de videochamadas, até os atendimentos cujos únicos elementos presentes são a voz do sujeito ou suas mensagens de texto. Assim, a presença ou não presença do corpo ganha particularidades a depender ainda do tipo de interação proposta no atendimento, o que pode ressoar na construção de um vínculo entre psicólogo e paciente. No caso do trabalho de Ruffo (2016), que realizou uma pesquisa com atendimentos via e-mail, os resultados mostraram satisfação dos usuários quanto ao atendimento realizado nessa modalidade, que não se diferenciou das propostas e desfechos de um suporte presencial.

Gumier (2015), que investigou a efetividade da psicoterapia mediada por computador com pessoas em relação abusiva com álcool, relatou o seu aspecto positivo para a redução do consumo de doses da bebida ao longo das semanas de tratamento. No entanto, ressaltou que as pesquisas sobre o tema ainda se mostram incipientes, convocando a categoria para a realização de mais estudos. Galvão (2019) expôs em sua pesquisa com clínica do trabalho via internet, alguns percalços como oscilações na internet, que por vezes faziam com o que o psicólogo não conseguisse escutar a totalidade do que havia sido dito pelo paciente. Em razão disso, relatou certa angústia por parte destes profissionais, que encontravam dificuldades no manejo do timing necessário ao fazer clínico, o que lhes demandou uma emergência criativa e espontânea, trabalho comum também na clínica presencial. Apesar disso, o estudo demonstrou que o estabelecimento de sentimentos de transferência e acolhimento ocorreram sem maiores diferenças em relação ao modelo presencial.

Donnamaria e Terzis (2011) também trazem, no artigo intitulado "Experimentando o dispositivo terapêutico de grupo via internet: primeiras considerações de manejo e desafios éticos”, as possíveis dificuldades trazidas pela imprevisibilidade 
característica ao uso da internet, que por vezes pode apresentar quedas e instabilidade. Além disso, ressaltam a falta de presença física do terapeuta, que o convoca a primazia da palavra diante da impossibilidade de dizer também pelo corpo. Como fator positivo, ressalta a possibilidade de atendimento àqueles com dificuldades de locomoção, e que por vezes acabavam por ficar desassistidos. Conclui, assim como Gumier (2015), a necessidade de mais pesquisas sobre essa prática, que por ainda serem escassas, não são capazes de firmar a eficácia necessária à sua regulamentação, embora a considerem promissora em seus trabalhos.

Em pesquisa realizada com grupos através da abordagem psicanalítica, de forma online, Donnamaria (2013) percebeu que as aflições causadas pelas dificuldades do contexto online foram perdendo força no decorrer das sessões, e os circuitos de transferências ocorreram sem grandes dificuldades. A adesão ao processo também não pareceu prejudicada pela terapêutica estar ocorrendo de forma online. Apesar das adaptações necessárias, os terapeutas responsáveis pela facilitação dos encontros não relataram diferenças significativas em seu desenrolar, se comparado ao formato presencial, mas pelo contrário, apontaram potencialidades em relação a este modelo. Este ponto é trazido em concordância nos trabalhos de Rodrigues (2014) e Pieta (2014): para a primeira, do ponto de vista da terapeuta, a experiência mostrou as semelhanças entre as duas modalidades, os atendimentos online proporcionam as mesmas emoções, sensações e receios do atendimento presencial. Já em Pieta (2014), além da perspectiva profissional, as/os usuárias/os do serviço psicológico também relataram não haver diferenças significativas entre a psicoterapia online e a presencial, apontando grande satisfação com a relação estabelecida na modalidade online. Rodrigues (2014) discute, no entanto, o cuidado que se deve ter em perceber as diferenças entre as modalidades, como a escolha de técnicas que possam já ter sido utilizadas e mostrado efetividade no contexto presencial mas que não são usualmente experienciadas no online.

De maneira geral, observou-se nos trabalhos que apesar de existirem diferenças entre um atendimento online e um presencial, estas diferenças não se configuram como impeditivas para a realização de uma psicoterapia, mas pelo contrário, trazem também fatores positivos. As relações de transferência, tanto em encontros grupais quanto individuais, mostraram-se possíveis nessa modalidade, e a desinibição causada pela falta de uma presença física surgiu em muitos trabalhos como um fator positivo, inclusive para a construção desse vínculo. Apesar de algumas distinções, na maior parte dos casos as minúcias presentes na construção de uma relação terapêutica se mostraram muito semelhantes em ambos os formatos de atendimento, seja em suas potencialidades ou em seus desafios. Ainda que alguns autores não tenham considerado possível chegar a uma conclusão acerca da eficácia da terapia online em razão dos poucos estudos sobre o assunto, a maioria deles a considerou promissora ou eficaz.

$\mathrm{Na}$ leitura e análise das resoluções publicadas pelo CFP, é possível apontar algumas lacunas presentes na legislação sobre a prática do atendimento online. Algumas ausências presentes na regulamentação são apontadas em alguns dos textos selecionados, porém tais produções estão limitadas em sua análise à vigência de uma resolução específica, a nº11/2012, como observado a seguir.

A primeira resolução, a $\mathrm{N}^{\circ}$ 03/2000, publicada em setembro de 2000, tem como mote a regulamentação do "atendimento psicoterapêutico mediado por computador", caracterizado na época como uma prática ainda não reconhecida pela psicologia (CFP, 2000). Desde o início, o atendimento de cunho psicoterapêutico só foi liberado na sua realização como parte de projetos de pesquisa, aprovado em comitê de ética ligado ao Conselho Nacional de Saúde, sendo vedada qualquer tipo de remuneração por essa atividade. Uma passagem do Art. 2 reflete bem a postura defendida pelo Conselho, colocando que o reconhecimento da validade dos resultados das pesquisas realizadas sobre a psicoterapia online dependeria de "ampla divulgação dos resultados e reconhecimento da comunidade científica". Foram reconhecidos, no entanto, serviços oferecidos por meio do computador, desde que não fossem psicoterapêuticos, sendo esses: "orientação psicológica e afetivo-sexual, desde que pontuais e informativos, orientação profissional, orientação de aprendizagem e psicologia escolar, orientação ergonômica, 
consultorias a empresas, reabilitação cognitiva, ideomotora e comunicativa, processos prévios de seleção de pessoal, utilização de testes informatizados devidamente validados, utilização de softwares informativos e educativos com resposta automatizada, e outros (...)" (CFP, 2000).

Um questionamento importante, que ecoa ao longo do desenvolvimento da legislação, é a separação colocada entre o atendimento psicoterapêutico e os serviços destacados anteriormente, notadamente a orientação psicológica e afetivo-sexual. Também questionava-se o que era entendido, pelo CFP, por orientação psicológica e por que ela não poderia ser psicoterapêutica. Para além do reconhecimento e autorização dos processos de seleção de pessoal e aplicação de testes psicológicos por esse meio virtual, a questão colocada anteriormente não é respondida. Outro ponto advindo da resolução presente é a identificação dos profissionais que oferecem o serviço. Na resolução inicial, as práticas reconhecidas tinham como requisito à sua realização a posse de uma identificação, que seria uma credencial eletrônica, no formato de um selo. Esse selo deveria estar atrelado ao endereço virtual que remetesse ao site do CFP, contendo o texto da resolução e os números de tais cadastros atualizados.

Além disso, haveria a conferência de um certificado específico para a realização do atendimento psicoterapêutico em caráter de pesquisa. Os cadastros deveriam ser feitos eletronicamente junto ao site do CFP, sendo de atribuição dos Conselhos Regionais a avaliação dos requerimentos e a fiscalização dos serviços (CFP. 2000). Referindo-se ao credenciamento para os atendimentos online que é produzida outra resolução, a $\mathrm{N}^{\circ}$ 06/2000, em dezembro do mesmo ano, com o propósito de instituir a Comissão Nacional de Credenciamento e Fiscalização dos Serviços de Psicologia pela Internet, criando um órgão nacional para cumprir tal função. Ao falarmos da aptidão para a realização das práticas psicológicas online, podemos pensar sobre esse ponto a partir de uma perspectiva legislativa, relativa a estar dentro da regulamentação de acordo com as normas do CFP para exercer tais atividades - normas essas que são bem determinadas desde a primeira resolução sobre o tema. No entanto, podemos pensar na aptidão em relação à formação específica para essas atividades. Em termos de documentos e orientações advindas diretamente das Resoluções, há uma notável escassez de produções por parte do CFP.

Em 2005, é produzida uma nova Resolução, a $N^{\circ} 12 / 2005$, revogando a $N^{\circ} 03 / 2000$. As principais mudanças identificadas foram, primeiramente, a permissão da cobrança pela realização dos serviços reconhecidos e distanciados da psicoterapia online citados anteriormente, condicionando essa liberação a não utilização do preço como propaganda para os serviços, salvaguardando o Art. 20 do Código de Ética Profissional do Psicólogo (CFP, 2005). E além deste item, o reforço do papel da Comissão Nacional de Credenciamento na regulamentação dos psicólogos para os serviços, expandindo os trâmites para esse processo. A avaliação das requisições foi determinada como papel da Comissão Nacional, sendo produzido um parecer a ser julgado por uma plenária composta no Conselho Regional referente. Quanto aos pontos destacados anteriormente, estes continuavam sem ser melhor explicitados ou até mencionados.

Como colocado anteriormente, algumas das produções selecionadas discutem pontos cegos e lacunas identificadas quanto à regulamentação do atendimento psicológico online no Brasil, traçando importantes questionamentos não somente sobre a dimensão legislativa, mas também pautando a dimensão ética da prática da Psicologia online. E como também já pontuado, as questões trazidas giram em torno da Resolução No 011/2012, por ser este o documento vigente na época. Destacamos inicialmente o artigo de Siegmund, Janzen, Gomes e Gauer (2015), no qual os autores trazem alguns pontos relevantes sobre a legislação vigente comparando-a com os panoramas gerais e as configurações legislativas de outros países. Os autores colocam que as regulamentações e as implicações das intervenções psicológicas on-line não haviam ainda recebido a atenção devida pela literatura especializada no país. Aponta-se uma falta de clareza quanto à terminologia relacionada a esse âmbito dentro da literatura. E também frente a uma análise dos estudos existentes, não encontrou-se um estudo específico sobre a resolução do CFP que estava vigente. As investigações sobre implicações éticas eram mais presentes 
internacionalmente, por meio de resoluções e códigos de ética, devido a um maior estabelecimento da prática em determinados países (Siegmund et. al, 2015).

Em termos de pontos críticos e lacunas presentes, o que é chamado como incompletude de tais pontos é atribuída a uma possível "pouca experiência profissional da psicologia brasileira com essas questões" (Siegmund et. al, 2015). A resolução em questão colocava apenas algumas modalidades de serviços psicológicos oferecidos por meios tecnológicos de comunicação à distância como práticas permitidas, sendo algumas delas as orientações psicológicas, limitadas a 20 encontros síncronos ou assíncronos, a supervisão pontual do trabalho de outros psicólogos e o atendimento eventual a clientes impossibilitados de comparecer ao atendimento presencial. Tais itens vão ser criticados pelos autores de forma geral pela falta de especificação e detalhamento presente. Em relação à modalidade orientação psicológica, sua falta de definição é questionada, principalmente em relação à modalidade de psicoterapia online, que na Resolução $N^{\circ}$ 011/2012, é restrita somente ao âmbito da pesquisa experimental. Nesse aspecto, as autoras Rodrigues e Tavares (2016) discutem que, parcialmente resguardados pelo conteúdo dessa resolução, alguns/as profissionais e suas/seus pacientes podem estar, na prática, realizando psicoterapia online. Partindo da consideração da Resolução No 011/2012 como insuficiente, as autoras aludem à dificuldade de o CFP e os Conselhos Regionais de Psicologia conseguirem fiscalizar cada profissional credenciado, argumentando também que a simples proibição da psicoterapia online pode ser considerada uma omissão da categoria, fomentando oportunidades para que outras profissões menos qualificadas passem a ocupar a correspondência dessa demanda.

Sobre o número de encontros previstos, coloca-se como sugestão uma melhor definição do que se configura como um contato virtual. A falta de definição também se faz presente nas menções às supervisões de outros profissionais e atendimentos remotos de clientes que realizam acompanhamento presencial. O termo utilizado é "eventual", o que deixa uma ambiguidade e não determina de maneira categórica o número de contatos que são possíveis de serem realizados em ambas as atividades (Siegmund et. al, 2015). Realizando a análise de tais aspectos na resolução seguinte, a de $\mathrm{N}^{\circ} 11$ de 2018, que tem como premissa regulamentar a prestação de serviços psicológicos no âmbito on-line, caracterizados como sendo "realizados por meio das tecnologias da informação e da comunicação", são autorizados, além de serviços já recorrentes em resoluções anteriores, como os processos de seleção de pessoal e a supervisão técnica de serviços ofertados por psicólogos, um conjunto de práticas classificadas como consultas e/ou atendimentos psicológicos, de diferentes tipos, de maneira síncrona ou assíncrona. Essa categoria é definida como um conjunto sistemático de procedimentos, por meio da utilização de métodos e técnicas psicológicas, do qual se presta um serviço nas diferentes áreas de atuação da Psicologia (CFP, 2018).

Na contramão do que foi instituído na resolução 011/12, há uma definição específica quanto às categorias regulamentadas, além da retirada de termos que suscitam certa indefinição, como no uso do termo eventual para descrever o caráter de frequência recomendado à realização da supervisão técnica e do atendimento a clientes impossibilitados de comparecer presencialmente. Também há uma remoção de menção a qualquer limite de encontros síncronos ou assíncronos para todas as práticas regulamentadas.

Compartilhando do mesmo objetivo, e também visando, entre outras coisas, a reflexão sobre os limites e as possibilidades da regulamentação das práticas psicológicas online, a dissertação de Luciana Ruffo (2016) promove questionamentos a respeito do fazer psicológico virtual e suas diferentes implicações, buscando obter uma melhor compreensão. Tais reflexões são precedidas por uma análise de um acompanhamento assíncrono realizado por e-mail. A autora refaz o percurso de chegada e início da prática de atendimentos psicólogos ofertados por computador, constatando que a abertura desta possibilidade e o crescente interesse por parte de psicólogos e clientes foi encarada pelo CFP com uma postura cautelosa, encaminhando uma comissão para o estudo da prática emergente, visto a falta de investigações sistemáticas sobre esse modelo. A autora questiona se houve de fato uma abertura do CFP e da categoria de psicólogos em geral para o acolhimento dessa nova demanda. 
Frente à ampla inserção do meio virtual na vida cotidiana, Ruffo (2016) indaga se os questionamentos sobre o meio pelo qual o atendimento ocorre não seria uma questão muito mais para o psicólogo do que para a pessoa que busca por ajuda através daquele canal, dado que a inserção do âmbito tecnológico no cotidiano é tanta a ponto de não enxergar mais o computador, por exemplo, como um mediador para a comunicação, colocando que a escrita de um e-mail estabelece um contato "tão real" quanto o outro quanto uma troca presencial, não questionando essa presença. A partir da referência a outros autores, situa-se a necessidade de conhecer pessoalmente o cliente a uma questão "geracional", que possivelmente estaria menos presente nos profissionais em alguns anos. A crescente popularidade do atendimento online gera uma tentativa de adaptação do modelo emergente ao universo da Psicologia tradicional. A autora coloca que, para ela, os questionamentos sobre as implicações da virtualidade no contato entre terapeuta e cliente não é mais presente, dada a banalização do uso da tecnologia.

Mas, a partir da posição do CFP na época da produção do texto, não recomendando a prática, e a nebulosidade dos motivos para tal, a autora propõe-se a trazer tais considerações. São retomadas, na forma de uma narrativa, discussões realizadas no ano de 2011, em seminários promovidos pelo Conselho Regional de São Paulo e o CFP, no sentido de analisar as práticas emergentes de atendimento online. Nas ocasiões, não foram encontradas justificativas para o impedimento da prática (Ruffo, 2016). Contudo, apesar de um movimento internacional de estudo, prática e liberação da psicoterapia pela internet em países como Estados Unidos e Israel, a postura adotada pelo Conselho na época foi de encaminhar mais estudos dentro da nossa realidade antes de uma liberação dado os "possíveis riscos".

Retomando a primeira resolução redigida pelo CFP sobre a questão, a $N^{\circ}$ 03/2000, é apontado um movimento de normatização e inibição da prática a partir do texto colocado. Como exemplo, tem-se o seguinte trecho: "São reconhecidos os serviços psicológicos mediados por computador, desde que não psicoterapêuticos, tais como orientação psicológica". (CFP, 2000). Alguns questionamentos são lançados a partir de uma análise desse trecho. Primeiramente, qual a razão para que uma orientação psicológica não possa ser considerada uma modalidade psicoterapêutica, e qual a compreensão de terapia que encaminha essa classificação. E além disso, o que se entende por orientação psicológica, tema abordado também no texto de Siegmund, Janzen, Gomes e Gauer (2015). Ruffo (2016) também atesta para a falta de definição quanto a essa classificação e critérios que diferenciam a orientação e o atendimento psicológico dentro dessa compreensão.

Na busca por mais definições, a autora não encontra referências que esclareçam tais questões. Em relação à orientação psicológica, as únicas referências ao termo encontram-se em textos de resoluções referentes ao atendimento online, fato que traz um questionamento sobre a origem do termo ter partido das próprias instâncias reguladoras, no sentido de cumprir um papel específico na sua criação. O CFP, na tentativa de dar continuidade ao trabalho realizado em instituições de ensino e coibir a prática da psicoterapia online por profissionais não vinculados a universidades, decide pelo caminho de nomear a prática como orientação (Ruffo, 2016), diferenciando esta da psicoterapia online, que só era permitida em um âmbito experimental segundo a resolução vigente. Alguns autores, ao buscar alguma delimitação da orientação psicológica, associa-se a seu aspecto breve e pontual, como também a ausência de formação de vínculo durante o processo. Questiona-se, a partir daí, qual a delimitação entre a orientação e a psicoterapia breve, visto que as duas modalidades compartilham de um tempo mais curto em seus processos.

Seguindo o caminho histórico de análise das resoluções, a autora contextualiza o surgimento da próxima regulamentação produzida pelo CFP na forma da Resolução $N^{\circ} 12 / 2005$, como sendo motivada pelo aumento de usuários de internet no país, que, segundo o IBGE, salta de 9,8 milhões no ano de 2000 para 32 milhões em 2005 (Ruffo, 2016). Tal resolução ampliou ainda mais o fato de a única possibilidade de realização dos atendimentos online serem em caráter experimental. Cria-se uma comissão para "avaliar e fornecer um selo de funcionamento a todo que qualquer profissional que se dispusesse a atender pelo meio virtual, mesmo em formato de orientação". A introdução dessa comissão de avaliação retoma 
questionamentos sobre a postura do CFP quanto à regulação, partindo de um sentimento de que este estaria tentando controlar os atendimentos já existentes, e normatizar ainda mais os atendimentos no meio virtual. A reflexão lançada questiona se há uma preocupação crescente do CFP a respeito de tal modalidade ou se o órgão estaria instituindo uma nova forma de controle da mesma frente ao aumento de interesse, visando evitar uma fuga ao modelo legalmente compreendido como "correto" (Ruffo, 2016).

A obtenção do selo de funcionamento durante a vigência da Resolução $N^{\circ}$ 12/2005 era realizado mediante a submissão de um site, local de referência para a realização dos atendimentos, para a comissão avaliadora do CFP, que não encontrando nenhuma irregularidade, permitiria que a imagem do selo fosse colocada no site, atestando o credenciamento junto ao CFP. Uma cartilha foi produzida na época contendo recomendações e instruções para as adequações que deveriam ser feitas nesses endereços eletrônicos, tais como: dispor sobre a privacidade e o sigilo garantido no processo, apontar possíveis interferências técnicas da internet, e ressaltar o limite de 10 atendimentos que era instituído na época, compreendendo atendimentos síncronos e assíncronos. Mais uma vez, a autora questiona a arbitrariedade da delimitação desse número. A resolução surgida no ano de 2012, já bastante discutida anteriormente, é situada no contexto geral como promovendo algumas mudanças, como o aumento do limite de atendimentos para 20 ao máximo, além da permissão de supervisões online e atendimentos a clientes presenciais que estivessem fora da região de origem e precisassem ser atendimentos virtualmente. Além disso, como aponta Ruffo (2016), o modelo do selo foi substituído por um cadastro online que pode ser consultado pela população.

Como já citado, uma nova resolução só veio em maio de 2018, sendo a de $\mathrm{N}^{\circ} 11 / 2018$. A expansão em relação às definições do meio onde os serviços são realizados, sendo caracterizados como TICs, é acompanhada de uma atualização dos serviços reconhecidos e liberados. Além daqueles já colocados anteriormente, ocorre a autorização de consultas e/ou atendimentos psicológicos de diferentes tipos, síncronos ou assíncronos. Em comparação às resoluções anteriores, a debatida categoria de orientação psicológica não encontra-se mais presente, bem como a separação entre esta prática, reconhecida e permitida a ser realizada profissionalmente, e a psicoterapia online, limitada ao âmbito da pesquisa, como também a um determinado número de encontros. No presente documento, encontramos uma ampliação dos serviços liberados de maneira irrestrita, bem como uma definição mais clara e delimitada da nova gama de práticas regulamentadas, dois pontos criticados nos textos referenciados anteriormente.

As consultas e/ou atendimentos psicológicos são definidos como "o conjunto sistemático de procedimentos, por meio da utilização de métodos e técnicas psicológicas do qual se presta um serviço nas diferentes áreas de atuação da psicologia com vistas à avaliação, orientação e/ou intervenção em processos individuais e grupais.” (CFP, 2018). E como também registrado anteriormente, a resolução explicita algumas restrições para o atendimento online, dada a ampliação promovida em seu escopo. Embora esse grande ponto de debate aparentemente tenha alcançado uma resolução, podemos apontar algumas ausências ainda notadas nesta, como pontuações sobre a formação teórica necessária para a atuação específica no meio das TICs, bem como as implicações da adaptação das técnicas e métodos, sendo essa ausência identificada nos documentos oficiais do Conselho. Nas produções analisadas, apesar de algumas delas atestarem a efetividade da aplicação de métodos tradicionais da Psicologia em contextos diferentes, uma discussão mais aprofundada sobre essa questão é pertinente.

E mais recentemente, em março de 2020, tivemos a promulgação da mais recente resolução, a No 04/2020. Como também já colocado, a produção foi realizada a partir do início da pandemia de covid-19. Em razão dessa conjuntura, a resolução em questão suspende os artigos da resolução anterior que dispunha sobre o processo de cadastro para a realização dos serviços psicológicos online, permitindo a admissão para a prática online a partir de um cadastro na plataforma online ePsi, e suspendendo também as restrições colocadas ao atendimento em determinados contextos. Pensando na transferência da maior parte das atividades dos profissionais da psicologia para o âmbito dito remoto, outro ponto que pode ser discutido é a 
realidade socioeconômica dos usuários desse atendimento, e consequentemente, a sua capacidade de acesso à internet. Considerando a crescente desigualdade social no Brasil e o grande número de pessoas que não possuem acesso à internet em seus domicílios, torna-se importante a realização de mapeamento deste panorama nos estudos sobre o tema.

No tocante aos pontos críticos da experiência da utilização da internet para o acompanhamento psicológico, Elza Rocha Pinto (2002) aponta a recorrente afirmação de que o estabelecimento da relação, em contexto terapêutico, é comprometido nesse meio. A autora aponta também outras objeções à terapia online, como a impossibilidade de observar expressões corpóreas, as pausas e silêncios que auxiliam na interpretação do discurso, pontos corroborados no estudo de Ana Paula Cavalcante dos Santos (2003), em que são citadas as dificuldades de comunicação, de expressão de sentimentos, percepção das reações do paciente e acesso aos elementos não-verbais como desvantagens da configuração online. É preciso ressaltar que estes estudos foram realizados quando a utilização dos serviços da psicologia online ainda era incipientes.

Portanto, no decorrer dos anos, outras produções demonstraram caminhos e conclusões diferentes das iniciais. Donnamaria (2013), ao discutir experiências grupais terapêuticas vivenciadas pela internet, reconhece o potencial da modalidade mas circula a necessidade de estudos que possam aprimorar os conhecimentos a respeito dessa forma de atuação, bem como a necessidade de uma formação teórico-técnica específica da/o profissional para este contexto. Esta dimensão também é avaliada em outros estudos: Machado e Barletta (2015) reiteram a necessidade de estudos sobre os usos das tecnologias em práticas clínicas supervisionadas, assim como Rodrigues e Tavares (2016), que sugerem a restrição do exercício da psicoterapia online a profissionais com especialização em psicologia clínica e o fomento, por parte do CFP, a iniciativas de cursos de formação especializada em psicoterapia online.

No contexto da clínica, a aliança terapêutica é um importante fundamento para qualquer abordagem que se siga. Pieta (2014) conclui que no tratamento online foi possível observar elementos da aliança terapêutica, que outrora acreditava-se ocorrer apenas na modalidade presencial. Outro ponto a respeito do qual há divergências se trata da questão do sigilo nessa forma de acompanhamento. Como mostra Azevedo, Silva e Ribeiro-Andrade (2015), cerca de sessenta por cento da amostra utilizada no estudo a respeito da psicoterapia mediada por computador acredita que a modalidade presencial é mais sigilosa do que a remota.

A psicoterapia online parece ser recebida de modo controverso por alguns profissionais, como mostra Ana Paula Cavalcante dos Santos (2003). Há, entre alguns profissionais, a crença de que a clientela que busca essa alternativa seria formada por indivíduos com dificuldade em relacionar-se com as outras pessoas e consigo mesmo/a, com tendência a retrair-se e esconder-se por trás das telas, para os quais um tratamento a distância auxiliaria no enfrentamento às resistências na psicoterapia. Neste levantamento realizado pela autora, portanto, muitos profissionais demonstraram insegurança ao tratar da eficácia e viabilidade do atendimento à distância; a discussão estava marcada pela divisão de opiniões extremas.

É necessário relembrar que até aquele presente momento — o ano de 2003 - as resoluções que tratavam do tema (a 03/2000 e a 06/2000) restringiam a modalidade à pesquisa autorizada previamente e sem cobrança, não havendo ainda uma ampla discussão e regulamentação detalhada. Para a primeira, a qual considerava que os efeitos do atendimento psicoterapêutico mediado pelo computador não eram conhecidos e devidamente estudados, e que não havia formação específica para os psicólogos nesse campo de conhecimentos, a modalidade se restringia à pesquisa autorizada previamente $\mathrm{e}$ sem cobranças à população pesquisada.

Parece consensual que essa modalidade exige um preparo específico por parte da profissão; se em 2003 a categoria apontava a necessidade, em 2019 esta preocupação continuou sendo pauta dos estudos que discutiam o tema. É o caso do que trazem Bazoni, Magalhães e Pereira (2019) no trabalho sobre as impressões de psicólogas/os sobre a orientação online. Alguns pontos levantados pelos participantes da pesquisa foram que o profissional precisa estar preparado e muito embasado, além de que não seria indicado para pacientes de risco e em crise, tratamentos graves e para crianças. Além disso, as autoras discutem 
que a última resolução publicada até aquele momento, a $\mathrm{N}^{\circ}$ 011/2018, não trata nominalmente a prática de psicoterapia online, nem traz condições técnicas mais específicas para a prática, o que colabora com a existência de lacunas no tema, trazendo algumas questões à dependência da interpretação e avaliação da/o própria/o profissional.

A dificuldade de trabalhar com uma intervenção que seja mais voltada aos aspectos corporais é trazida no estudo de Bazoni, Magalhães e Pereira (2019), a partir de um dos depoimentos dos entrevistados. Esse aspecto encontra correspondência em outros estudos: nessa modalidade há uma maior dificuldade para terapeutas interpretarem a linguagem corporal dos pacientes e destes de expressarem emoções, a impossibilidade de avaliar o indivíduo de forma mais completa, implicando adaptações nas questões de manejo e até mesmo impossibilidade de utilização de trabalhos corporais (Ana Paula Cavalcante dos Santos, 2003; Donnamaria e Terzis, 2013; Pieta, 2014; Siegmund e Lisboa, 2015). Essas afirmativas, no entanto, não são unânimes. O fazer presencial não está atrelado necessariamente ao corpo a corpo, a presença é resultado da produção de um espaço comum, quando o cliente se sente realmente acompanhado, independente de ser concreto ou online, como apontam Bazoni, Magalhães e Pereira (2019). No psicodrama, também, a distância não parece ser impeditiva à aplicação da abordagem: Vidal e Cardoso (2020) trazem relatos de duas experiências bem sucedidas utilizando o método da psicoterapia da relação e o da técnica do psicodrama interno. Elas apontam, ainda, que o psicodrama online, mesmo que muito recente, é uma alternativa frente às impossibilidades presenciais de levar o psicodrama às pessoas e aos lugares novos.

\section{Considerações Finais}

É possível observar um considerável aumento das produções acerca das práticas psicológicas no meio virtual ao longo dos anos, em conformidade com as mudanças sugeridas pelas publicações de novas resoluções pelo CFP. Com o crescente interesse por parte da categoria profissional acerca das possibilidades do fazer psicológico nesse contexto, os estudos tornaramse cada vez mais específicos: enquanto os iniciais tinham por objetivo pesquisar a viabilidade da atuação online, sendo esta realizada apenas com fins exploratórios, os trabalhos mais recentes trataram de temas mais característicos à psicologia dentro dessa modalidade.

Muitos dos trabalhos selecionados apresentam como objetivo investigar a efetividade dessa prática, principalmente no que tange à possibilidade de construção de um vínculo terapêutico, além de trazerem a ética como fundante à discussão. A partir dessa compreensão e dos achados trazidos nesta revisão de literatura, observa-se que as práticas psicológicas online são ética e tecnicamente possíveis. Foi percebida a necessidade de desenvolvimento de estudos futuros sobre o tema, em busca de abarcar cada vez mais as possibilidades e entender os possíveis obstáculos na prática.

É importante apontar que o caminho do desenvolvimento dessa discussão foi marcado tanto por concordâncias como por divergências, como visualizado no decorrer desta pesquisa. Alguns pontos, como a definição e a classificação das atividades regulamentadas, bem como a restrição ao número de encontros virtuais permitidos, estiveram presentes ao longo das resoluções, sendo atualizados conforme o avanço do debate e das produções. No entanto, algumas questões ainda configuramse como ausentes, a exemplo da formação teórica para a atuação no meio online.

Ademais, considerando outras ausências nos trabalhos analisados, como a escassez de produções nas regiões Nordeste e Norte, e a falta de trabalhos com e sobre populações economicamente vulneráveis, na qual o acesso ao meio virtual pode ser mais difícil, avaliamos a necessidade de novas produções que levem em conta esses diferentes aspectos que se articulam à prática da psicologia no meio online, especialmente dada à maior importância adquirida por essa modalidade nos tempos atuais. 


\section{Referências}

Aquino, E. M., Silveira, I. H., Pescarini, J. M., Aquino, R., Souza-Filho, J. A. D., Rocha, A. D. S., \& Lima, R. T. D. R. S. (2020). Medidas de distanciamento social no controle da pandemia de COVID-19: potenciais impactos e desafios no Brasil. Ciência \& Saúde Coletiva, 25, 2423-2446.

Azevedo, B., Silva, É \& Ribeiro-Andrade, É. H. (2015). Estudos sobre a psicoterapia mediada por computador. Perspectivas Online: Humanas \& Sociais Aplicadas, 5(14).

Bittencourt, H. B., Rodrigues, C. C., dos Santos, G. L., da Silva, J. B., de Quadros, L. G., Mallmann, L. S., \& Fedrizzi, R. I. (2020). Psicoterapia on-line: uma revisão de literatura. Diaphora, $9(1), 41-46$

Botelho, L. L. R., de Almeida Cunha, C. C., \& Macedo, M. (2011). O método da revisão integrativa nos estudos organizacionais. Gestão e sociedade, 5(11), pp. 121-136.

Conselho Federal de Psicologia. (2000a). Resolução CFP $n^{\circ}$ 003, de 25 de setembro de 2000. Regulamenta o atendimento psicoterapêutico mediado por computador. Brasília, DF. https://www.crprs.org.br/upload/legislacao/legislacao40.pdf

Conselho Federal de Psicologia. (2000b). Resolução CFP n ${ }^{\circ}$ 006, de 16 de dezembro de 2000. Institui a Comissão Nacional de Credenciamento e Fiscalização dos Serviços de Psicologia pela Internet. Brasília, DF. https://site.cfp.org.br/wp-content/uploads/2000/12/resolucao2000_6.pdf

Conselho Federal de Psicologia. (2005). Resolução $n^{o}$ 012, de 18 de agosto de 2005. Regulamenta o atendimento psicoterapêutico e outros serviços psicológicos mediados por computador e revoga a Resolução $C F P N^{\circ} 003 / 2000$. Brasília, DF.

Conselho Federal de Psicologia. (2012). Resolução no 011, de 21 de junho de 2012. Regulamenta os serviços psicológicos realizados por meios tecnológicos de comunicação a distância, o atendimento psicoterapêutico em caráter experimental e revoga a Resolução CFP N. ${ }^{o}$ 12/2005. Brasília, DF. https://site.cfp.org.br/wp-content/uploads/2012/07/Resoluxo_CFP_nx_011-12.pdf

Conselho Federal de Psicologia. (2018). Resolução $n^{o}$ 011, de 11 de maio de 2018. Regulamenta a prestação de serviços psicológicos realizados por meios de tecnologias da informação e da comunicação e revoga a Resolução CFP N. ${ }^{o} \quad 11 / 2012 . \quad$ Brasília, DF. https://site.cfp.org.br/wpcontent/uploads/2018/05/RESOLU\%C3\%87\%C3\%83O-N\%C2\%BA-11-DE-11-DE-MAIO-DE-2018.pdf

Conselho Federal de Psicologia. (2020a). Resolução $n^{\circ}$ 04, de 26 de março de 2020. Dispõe sobre regulamentação de serviços psicológicos prestados por meio de Tecnologia da Informação e da Comunicação durante a pandemia do COVID-19. Brasília, DF. https://atosoficiais.com.br/cfp/resolucao-do-exercicioprofissional-n-4-2020-dispoe-sobre-regulamentacao-de-servicos-psicologicos-prestados-por-meio-de-tecnologia-da-informacao-e-da-comunicacao-durante-apandemia-do-covid-19?origin=instituicao\&q=004/2020

Conselho Federal de Psicologia (2020c). Práticas e estágios remotos em Psicologia no contexto da pandemia da Covid-19: recomendações, de 25 de agosto de 2020. Brasília, DF. https://site.cfp.org.br/wp-content/uploads/2020/08/Caderno-de-orientac\%CC\%A7o\%CC\%83es-formac\%CC\%A7a\%CC\%83o-eesta\%CC\%81gios_FINAL2_com_ISBN_FC.pdf

Conselho Federal de Psicologia. (2020d). Nota orientativa sobre ensino da Avaliação Psicológica em modalidade remota no contexto da pandemia do Covid19, de 17 de novembro de 2020. Brasília, DF. https://site.cfp.org.br/wp-content/uploads/2020/11/Nota-Orientativa-sobre-ensino-daAvalia\%C3\%A7\%C3\%A3o-Psicol\%C3\%B3gica-em-modalidade-remota-no-contexto-da-pandemia-de-Covid.pdf

Conselho Federal de Psicologia (2020e). Nota orientativa sobre o uso de testes psicológicos/computadorizados elou de aplicação remota/online, de 17 de novembro de 2020. Brasília, DF. https://site.cfp.org.br/wp-content/uploads/2020/11/Nota-orientativa-sobre-o-uso-de-testes-psicol\%C3\%B3gicosinformatizados.pdf

Costa Pitta, L. S., Hipolito, R. L., dos Santos Rocha, L. C., Sales, F. M., da Silva, L. P. M., \& Flores, P. V. P. (2021). Alterações tomográficas pulmonares no COVID-19: revisão integrativa da literatura. Research, Society and Development, 10(13), e308101321194-e308101321194.

Donnamaria, C. P., \& Terzis. A., (2011). Experimentando o dispositivo terapêutico de grupo via internet: primeiras considerações de manejo e desafios éticos. Revista da SPAGESP - Sociedade de Psicoterapias Analíticas Grupais do Estado de São Paulo, 12, 17-26.

Donnamaria, C. P. (2013). Experiências de um atendimento psicológico grupal via internet: uma perspectiva psicanalítica. Tese de Doutorado. Pontifícia Universidade Católica. Campinas, SP

Galvão, M. G. A. (2019). Atendimento online em clínica do trabalho: estudo exploratório. Dissertação de mestrado. Universidade de Brasília. Brasília, DF.

Gumier, A. B. (2014). Terapia por internet para dependentes de álcool: desenvolvimento de um protocolo de pesquisa e intervenção. Dissertação de mestrado. Universidade Federal de Juiz de Fora. Juiz de Fora, MG.

Machado, G. I. M. D. S., \& Barletta, J. B. (2015). Supervisão clínica presencial e online: percepção de estudantes de especialização. Revista Brasileira de Terapias Cognitivas, 11(2), 77-85.

Magalhães, L T., Bazoni, A. C., \& Pereira F. N. (2019). Impressões de psicólogos clínicos acerca da orientação psicológica online. Revista Brasileira de Psicoterapia, 21(1), 53-69.

Marot, R. S. V., \& Ferreira, M. C. (2008). Attitudes sobre a aprovação da psicoterapia online da Teoria de Ação Racional. Revista Interamericana de Psicologia, 42, 317-324.

Mendes, K. D. S., Silveira, R. C. D. C. P., \& Galvão, C. M. (2008). Revisão integrativa: método de pesquisa para a incorporação de evidências na saúde e na enfermagem. Texto \& contexto-enfermagem, 17, 758-764.

Ministério da Educação (2020). Portaria $n^{a}$ 544, de 16 de junho de 2020. Dispõe sobre a substituição das aulas presenciais por aulas em meios digitais, enquanto durar a situação de pandemia do novo coronavírus - Covid-19, e revoga as Portarias MEC $n^{\circ} 343$, de 17 de março de 2020 , $n^{\circ} 345$, de 19 de março 
Research, Society and Development, v. 10, n. 14, e454101422266, 2021

(CC BY 4.0) | ISSN 2525-3409 | DOI: http://dx.doi.org/10.33448/rsd-v10i14.22266

de 2020, e $n^{\circ}$ 473, de 12 de maio de 2020. Brasília, DF. Disponível em: https://www.in.gov.br/en/web/dou/-/portaria-n-544-de-16-de-junho-de-2020261924872

Moraes, R. F. D. (2021). A Segunda onda da pandemia (mas não do distanciamento físico): covid-19 e políticas de distanciamento social dos governos estaduais no Brasil (Nota técnica $\mathrm{n}^{\circ} 31$ ). http://repositorio.ipea.gov.br/handle/11058/10442

Paiva, M. R. F., Parente, J. R. F., Brandão, I. R., \& Queiroz, A. H. B. (2016). Metodologias ativas de ensino-aprendizagem: revisão integrativa. SANARERevista de Políticas Públicas, 15(2).

Pieta, M. A. M. (2014). Psicoterapia pela Internet: A relação terapêutica. Tese de doutorado. Universidade Federal do Rio Grande do Sul. Porto Alegre, RS.

Pinto, E. R. (2002). As modalidades do atendimento psicológico on-line. Temas em Psicologia, 10, 167-178

Rezende, G. D. E S.., Alves, A. L. F., \& Rabelo, A. F. A. (2021). Aplicativos móveis desenvolvidos para Educação em Saúde no mundo: revisão integrativa da literatura. Research, Society and Development, 10(13).

Rodrigues, C. G. (2014). A aliança terapêutica na psicoterapia breve online. Tese de doutorado. Universidade de Brasília. Brasília, DF.

Rodrigues, C. G., Tavares, M. A. (2016). Psicoterapia online: demanda crescente e sugestões para regulamentação. Psicologia em Estudo, $21,735-744$.

Ruffo, L. (2016). Ensaios para compreensão de uma prática psicológica em construção: atendimento online (via e-mail). Dissertação de mestrado. Universidade de São Paulo.

Santos, A. P. C. (2003). Psicoterapia na rede: um estudo sobre a clínica mediada pelo computador. Dissertação de mestrado. Pontifícia Universidade Católica.

Siegmund, G., \& Lisboa, C. (2015). Orientação psicológica on-line: percepção dos profissionais sobre a relação com os clientes. Psicologia: Ciência $e$ Profissão, 35, 168-181.

Siegmund, G., Janzen, M. R., Gomes, W. B., \& Gauer, G. (2015). Aspectos éticos das intervenções psicológicas on-line no Brasil: situação atual e desafios. Psicologia em Estudo, 20(3), 437-447.

Singulane, B. A. R. (2016). Aliança terapêutica e satisfação com o tratamento na psicoterapia por internet para dependentes de álcool. Dissertação de mestrado. Universidade Federal de Juiz de Fora. Juiz de Fora, MG.

Viana, D. M. (2020). Atendimento psicológico online no contexto da pandemia de Covid-19. Cadernos ESP - Revista Científica da Escola de Saúde Pública do Ceará, 14(1), 74-79.

Vidal, G. P., \& Castro, A. (2020). O psicodrama clínico on-line: uma conexão possível. Revista Brasileira de Psicodrama, $28,54-64$.

Vidal, G. P., \& Cardoso, A. S. (2020). Dramatização on-line: psicoterapia da relação e psicodrama interno no psicodrama contemporâneo. Revista Brasileira de Psicodrama, 28, 131-141. 